\title{
Endoscopic laser palliation for advanced malignant dysphagia
}

\author{
S G BOWN, R HAWES, K MATTHEWSON, C P SWAIN, H BARR, \\ P B BOULOS, AND C G CLARK \\ From the National Medical Laser Centre, Department of Surgery, University College Hospital, London
}

\begin{abstract}
SUMmaRY Palliative treatment of malignant dysphagia aims to optimise swallowing for the maximum time possible with the minimum of general distress to these seriously ill patients. Thirty four patients considered unsuitable for surgery because of advanced malignancy, other major pathology or in whom previous surgery had been unsuccessful were treated endoscopically with the Nd YAG laser. Significant improvement was achieved in $29(85 \%)$. On a scale of $0-4(0=$ normal swallowing; $4=$ dysphagia for all fluids), mean improvement was $1 \cdot 7$, with 25 patients $(74 \%)$ able to swallow most, or all solids after treatment. With increasing experience, the average number of treatment sessions required for each patient became less; initial time in hospital became comparable to that needed for intubation. Failures were caused by inappropriate patient selection (3), or laser related perforation (2). The mean survival in the whole group was 19 weeks (range 2-44). Eighteen patients needed further treatment for recurrent dysphagia, a mean of six weeks (range 2-15) after initial therapy. Ten of these responded, but eight eventually required insertion of a prosthetic tube. The duration of good palliation was very variable after initial laser therapy.
\end{abstract}

Most patients with oesophageal carcinoma have disease advanced beyond hope of curative treatment at the time of presentation. In a paper reviewing published results on over 83000 patients, Earlam and Cunha-Melo,' showed that of 100 patients who present with malignant dysphagia, on average only 39 prove to be resectable, 26 leave hospital, and only four patients will be alive at five years. In a recent personal series of 130 , Watson ${ }^{2}$ considered $38 \%$ to be resectable, although many of these resections were only palliative. With such a poor long term outlook, the main aim of treatment is frequently palliation to relieve symptoms and improve the quality of life, with minimum morbidity from the treatment itself. Local tumour bulk is the major cause of dysphagia as it occludes the oesophageal lumen and makes adequate nutritution difficult or impossible.

There are a number of palliative treatments avail-

Address for correspondence: Dr S G Bown, National Medical Laser Centre, Department of Surgery, Rayne Institute, 5 University Street, London WC1E $6 \mathrm{JJ}$.

Received for publication 20 October 1986. able, each with advantages and disadvantages. Surgery probably provides the best palliation if the patient is fit enough, but the mortality and morbidity can be high.' Radiotherapy with current techniques has a low mortality, but prolonged morbidity, and slow relief of dysphagia. ${ }^{3}$ Repeated bougienage becomes an increasing burden and as the disease progresses is more difficult, more painful and provides less benefit for shorter intervals each time. ${ }^{+}$ Chemotherapy has only a small part to play at present in the treatment of oesophageal cancer, although some responses have been reported with cisplatin. ${ }^{5} \mathrm{~A}$ gastrotomy tube provides a route for nourishment, but does not help dysphagia. For patients who are unfit for major surgery, the most effective established technique for relieving obstruction is insertion of a prosthetic tube, although many question the quality of the palliation achieved.' In 1982 Fleischer first reported the effectiveness of the Nd YAG laser in reestablishing patency through malignant stenoses of the oesophagus" and his results have been confirmed by other groups since. ${ }^{7-12}$ All have reported improved 
swallowing ability in the majority of patients and have been relatively consistent with regards to the choice of patient groups, laser parameters used, immediate clinical benefits, and acute complication rate. Reports to date have dealt primarily with the results of the first laser course, however, with few reporting long term follow up in any detail, particularly the incidence of recurrent dysphagia and its subsequent management. The purpose of this paper is to present the results of both initial laser treatment and subsequent follow up to identify how this new treatment can be applied most effectively to give good and prolonged palliation with a minimum of general upset to these patients who have such a limited life expectancy.

\section{Methods}

\section{PATIENTS}

The study group consisted of 34 consecutive patients treated at University College Hospital, London for whom detailed follow up data were available. There were 27 men and seven women with a mean age of 71 years (range 52-88). All had dysphagia caused by advanced malignant disease of the oesophagus or gastric cardia that was considered incurable at the time of referral. The mean tumour length was $8.0 \mathrm{~cm}$ (range 3-15 cm). Histologically, 12 were squamous and 22 adenocarcinomas. Three $(9 \%)$ were cervical (origin at $15-22 \mathrm{~cm}), 14(41 \%$ ) were mid-oesophageal (origin 23-34 $\mathrm{cm}$ ) and $17(50 \%$ ) started in the distal oesophagus or gastric cardia (origin below $34 \mathrm{~cm}$ ). Eight patients were considered unfit for surgery or radiotherapy because of the advanced state of their malignancy, and 12 others were considered unfit because of other serious pathology (mostly cardiorespiratory disease). Six had undergone operation with a view to resection, but not only had the tumour proved too advanced to resect, but dilatation of the stenosis adequate to insert a prosthetic tube had proved impossible. Two had previously had a prosthetic tube inserted but discomfort from the tube had been severe enough for the patient to request its removal and seek alternative treatment. Four had anastomotic recurrences after earlier resections of the oesophagus or gastric cardia but were considered unfit for further surgery, one had tumour overgrowing a Celestin tube and one refused surgery.

\section{ENDOSCOPIC TECHNIQUE}

All procedures were performed using a 100 watt $\mathrm{Nd}$ YAG laser (Fiberlase 100, Pilkington Medical Systems Ltd, Glasgow). The laser light is delivered through a single flexible fibre $(0.4 \mathrm{~mm}$ diameter $)$ enclosed in a Teflon sheath $(2.3 \mathrm{~mm}$ diameter $)$ through which coaxial carbon dioxide gas is delivered. The gas serves to cool the fibre tip and prevents debris from sticking. This catheter system is passed down the biopsy channel of a standard flexible gastroscope fitted with an appropriate safety filter in the eyepiece. A small nasogastric tube is placed alongside the endoscope into the proximal oesophagus during treatment and attached to a chest drain bottle. This system allows the carbon dioxide gas to escape thus preventing overdistension of the viscus, and it also traps the smoke produced making the environment more pleasant for the patient and staff. Patients were sedated with intravenous diazemuls $(5-10 \mathrm{mg})$ sometimes with the addition of pethidine $(25-50 \mathrm{mg})$. In one patient with a tumour of the cervical oesophagus general anaesthesia was used.

The tip of the fibre was held $5-10 \mathrm{~mm}$ from the target (always avoiding tissue contact) with power settings ranging between $60-80$ watts and shots of one second duration.

The aim was to destroy as much intraluminal tumour as could be done safely. Some tissue vaporised immediately with each laser shot while adjacent areas were necrosed and either sloughed over a few days or healed with fibrosis. Treatment was directed at the parts of the tumour causing the worst obstruction and proceeded to shave the occluding nodules back towards, but not quite as far as, the normal oesophageal wall. Whenever possible, treatment started at the distal margin of the tumour because immediate oedema in unvaporised areas after therapy could hinder progress in the opposite direction. In some cases, the endoscope could not be negotiated past the lesion initially, even after dilatation, and treatment had to start proximally. With tight stenoses, immediate oedema was reduced by lowering the laser power to about $15 \mathrm{~W}$ and fitting a sapphire tip to the laser fibre (Surgical Laser Technologies, Keighley). This can be used in direct contact with tissue and acts like a hot knife. ": All accessible tumour was treated at each session, and treatment repeated at intervals of three to four days (to allow necrosed tumour to slough) until full recanalisation was achieved. The early cases were followed up as outpatients, and endoscopy repeated if dysphagia recurred, although more recently our policy has changed, and all patients now have repeat endoscopies three to four weeks after the initial course of treatment to assess the result and treat remaining intraluminal tumour if required. For those with recurrent dysphagia, subsequent management depended on the endoscopic findings. Those with recurrent exophytic tumour were treated with the laser again, whereas those without obvious endoscopically accessible tumour were treated by dilatation and insertion of a Celestin tube. 
Table 1 Treatment parameters for first and second courses of laser treatment

\begin{tabular}{|c|c|c|}
\hline & First course & Second course \\
\hline $\begin{array}{l}\text { Mcan number of } \\
\text { scssions (rangc) }\end{array}$ & $2 \cdot 7(1-6)$ & $1 \cdot 6(1-3)$ \\
\hline $\begin{array}{l}\text { Laser energy delivered } \\
\text { (Joules per session) }\end{array}$ & $4400(600)-115(0))$ & $4500(1000-10000)$ \\
\hline $\begin{array}{l}\text { Laser energy delivered } \\
\text { (Joules per course) }\end{array}$ & $12000(600)-45(000)$ & $7500(3000)-29000)$ \\
\hline $\begin{array}{l}\text { Duration of coursc } \\
\text { (days) }\end{array}$ & $9(1-30)$ & $4(1-15)$ \\
\hline Nights in hospital & $16(0-60)$ & $4(0-30)$ \\
\hline
\end{tabular}

\section{Results}

Table 1 shows the details of the first laser course for all patients and of the second course for the 13 patients who had recurrent dysphagia caused by exophytic tumour which could be treated by further laser therapy. There was no difference in response between squamous and adenocarcinomas. In 20 patients, long term relief of dysphagia was achieved with the laser alone. Ten received only one laser course (one also had a single bougie dilatation seven weeks after treatment and one also had a course of radiotherapy). Ten patients had two or more laser courses, but were able to maintain good swallowing ability. Eight patients had good results from one or more laser courses, but later had recurrent dysphagia that was not caused by exophytic tumour, and so were treated by insertion of a Celestin tube. There were four major complications related to the intubation procedure (one death shortly after anaesthesia, one aspiration pneumonia and two perforations (one fatal)). One other patient had a tube inserted shortly after laser treatment despite a good functional result to protect the lumen from oedema during a course of radiotherapy. Only one other patient had radiotherapy after laser treatment in the hope of achieving a good long term result. Unfortunately, he tolerated the radiotherapy poorly and died of pneumonia eight
Table 3 Patients with unsuccessful laser therapy

\begin{tabular}{llll}
\hline Reason for failure & $\begin{array}{l}\text { Patients } \\
(n)\end{array}$ & $\begin{array}{l}\text { Treatment } \\
\text { given }\end{array}$ & $\begin{array}{l}\text { Survival } \\
\text { (weeks) }\end{array}$ \\
\hline $\begin{array}{l}\text { Inappropriate patient } \\
\text { selection: }\end{array}$ & 2 & $\begin{array}{l}\text { Terminal care } \\
\text { Prosthetic tubc } \\
\text { (introduction caused } \\
\text { perforation) }\end{array}$ & 2,3 \\
$\begin{array}{l}\text { (a) patient too ill } \\
\text { (b) tumour mainly } \\
\text { extrinsic }\end{array}$ & 1 & $\begin{array}{l}\text { (a) surgical intubation } \\
\text { (b) retrostcrnal pull up }\end{array}$ & 1 \\
Laser perforation & 2 & & \\
\hline
\end{tabular}

weeks after completing the laser course, although he had no problems with recurrent dysphagia, even without a tube. Two patients had incomplete laser courses. Both had one laser treatment but were severely debilitated and further intervention was not felt to be justified. They died 16 and 18 days later and neither experienced any real benefit from the treatment. Details of survival times and the intervals from treatment to recurrent dysphagia are given in Table 2 and of the five failures of initial laser treatment in Table 3. An overall summary of patient care is shown in Figure 1. The mean survival for the group as a whole was 19 weeks (range 2-44). Twenty patients survived more than three months, eight patients more than six months, two patients more than nine months but none survived for a year. For the subgroup of patients who were successfully treated with laser alone, their mean survival was 21 weeks (range 6-44). The mean time since initial treatment for the six patients still alive is nine weeks (range 3-13). Swallowing was graded on a scale of $0-4$ before and after treatment for each patient, and the results are shown in Figure 2. At presentation, none could swallow more than semi-solids, $13(38 \%)$ could only manage fluids and five $(15 \%)$ could hardly swallow their own saliva. After treatment, 29 (85\%) showed improvement and $25(74 \%)$ were able to swallow most or all solids. The mean improvement in swallowing was 1.7 grades (range $0-4$ ) on the

Table 2 Follow-up for patients with successful initial laser therapy. The second column indicates the time from the end of the initial course to the start of the second course of treatment and the third column indicates the time from the end of the second course until death. The survival time given is that from the first laser session until death

\begin{tabular}{|c|c|c|c|c|}
\hline & Patients $(n)$ & $\begin{array}{l}\text { Time to second } \\
\text { intervention (weeks) }\end{array}$ & $\begin{array}{l}\text { Time from second } \\
\text { intervention to death } \\
\text { (weeks) }\end{array}$ & Total survival time (weeks) \\
\hline One laser coursc & 10 & - & - & $17^{*}(6,8,18,19,21,27)$ \\
\hline Two or more laser courses & 10) & $5(2-11)$ & $15(4-34)$ & $24 \dagger(11,16,16,18,20,25,42,44)$ \\
\hline One laser course later Celestin & 5 & $10(5-15)$ & $4(0-8)$ & $18(11,16,17,18,27)$ \\
\hline Two or more laser courses, later Celestin & 3 & $5(3-6)$ & & $28(20,29,34)$ \\
\hline One laser course with immediatc Celestin & 1 & & & $16 \ddagger$ \\
\hline
\end{tabular}

${ }^{*}$ Four patients alive at $3,3,10$, and 11 wecks; †two patients alive at 12 and 13 wecks; $\ddagger$ despite successful laser course, Celestin tube placed to protect luminal patency during subsequent radiotherapy. 


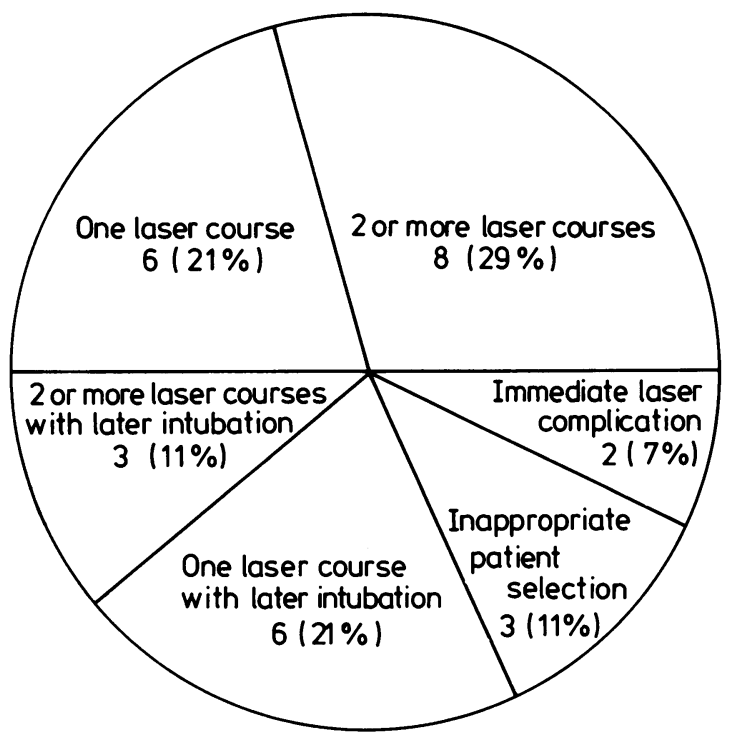

Fig. 1 Overall results of laser treatment for the 28 patients who had died at the time of writing.

dysphagia scale shown in Figure 2. Follow up data on patient weight was available for 20 patients. Nine gained more than $1 \mathrm{~kg}$ (mean $3.5 \mathrm{~kg}$, range $1-6$ ) and three more were able to maintain their weight for at least 12 weeks after treatment.

Several patients had vague chest pains at the time of presentation, presumably related to the tumour and commented that these diminished after treatment. Others complained of mild chest pains after laser sessions, sometimes associated with a pyrexia, but these always settled within $24-48$ hours.

\section{Discussion}

Patients currently selected for endoscopic treatment of oesophageal cancer are those with advanced disease who have a relatively short life expectancy. The dominant symptom is dysphagia and the prime objective is to restore swallowing ability as closely as possible to normal and maintain this for the remainder of the patient's life, with the minimum of disturbance to these seriously ill patients. The results

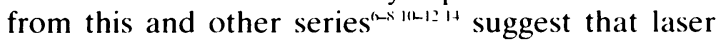
treatment can provide good palliation with low morbidity in a high percentage of cases. The question is now whether this new procedure has been developed to its full potential and how it compares with the other principle endoscopic approach, the insertion of a prosthetic tube. The main differences are seen in patient selection, technique, complications, quality of palliation and the need for subse- quent intervention. Survival time depends largely on the stage of the disease at the time of presentation and would not be expected to be significantly altered by a purely palliative procedure, although improved nutrition with good palliation of dysphagia could have some influence. The average survival of 19 weeks is comparable with that of other laser series (Fleischer 14 weeks, ${ }^{16}$ Mellow 21 weeks ${ }^{14}$ and after intubation (Ogilvie 24 weeks) ${ }^{16}$ ).

Laser therapy aims to debulk intraluminal tumour, and is only possible if the main bulk causing obstruction is exophytic and endoscopically accessible. This is the case for most primary tumours of the oesophagus, although is rarely so for tumours compressing or invading the oesophagus from outside the lumen. The latter together with those that have developed a spontaneous perforation or tracheooesophageal fistula can only be helped by intubation. It may be possible to treat submucosal tumours if their extent is precisely defined by computed tomography scans or endoscopic ultrasound, but this requires burning through normal mucosa to gain access to the tumour and carries a higher risk of perforation. ${ }^{17}$ The laser has the advantage that no foreign body is left in the gastrointestinal tract, and can be used in the cervical oesophagus where a tube could not be tolerated.

Insertion of a tube with the aid of a guide wire is usually technically straightforward although it can be uncomfortable for the patient unless general anaesthesia is used. In some patients, however, tortuosity of the stenosed oesophageal lumen makes insertion of the guide wire impossible. The high incidence of this in this series (seven cases, in four of whom the wire could not even be inserted at an open surgical procedure) reflects selective referral of intubation failures, and is a good indication for laser treatment. as successful recanalisation was achieved in five of the seven. Intubation has the advantage of only requiring one endoscopy, whereas laser recanalisation requires several and on average, each patient in this series required 2.7 sessions for recanalisation, spread over nine days. However, with increasing experience few patients now require more than two treatments initially and with twice weekly endoscopy, this means that the course can be finished in less than a week. Patients who are otherwise well enough can be treated as day cases. The time in hospital for the later cases in our series now compares favourably with the average of five days reported for uncomplicated intubations." Second and subsequent laser courses were even shorter (Table 1) and often just involved a single day case endoscopy. It is possible that more treatments could be completed in one session if general anaesthesia was used, as in the case of laser treatment of tracheobronchial tumours, ${ }^{\text {" }}$ but this has 


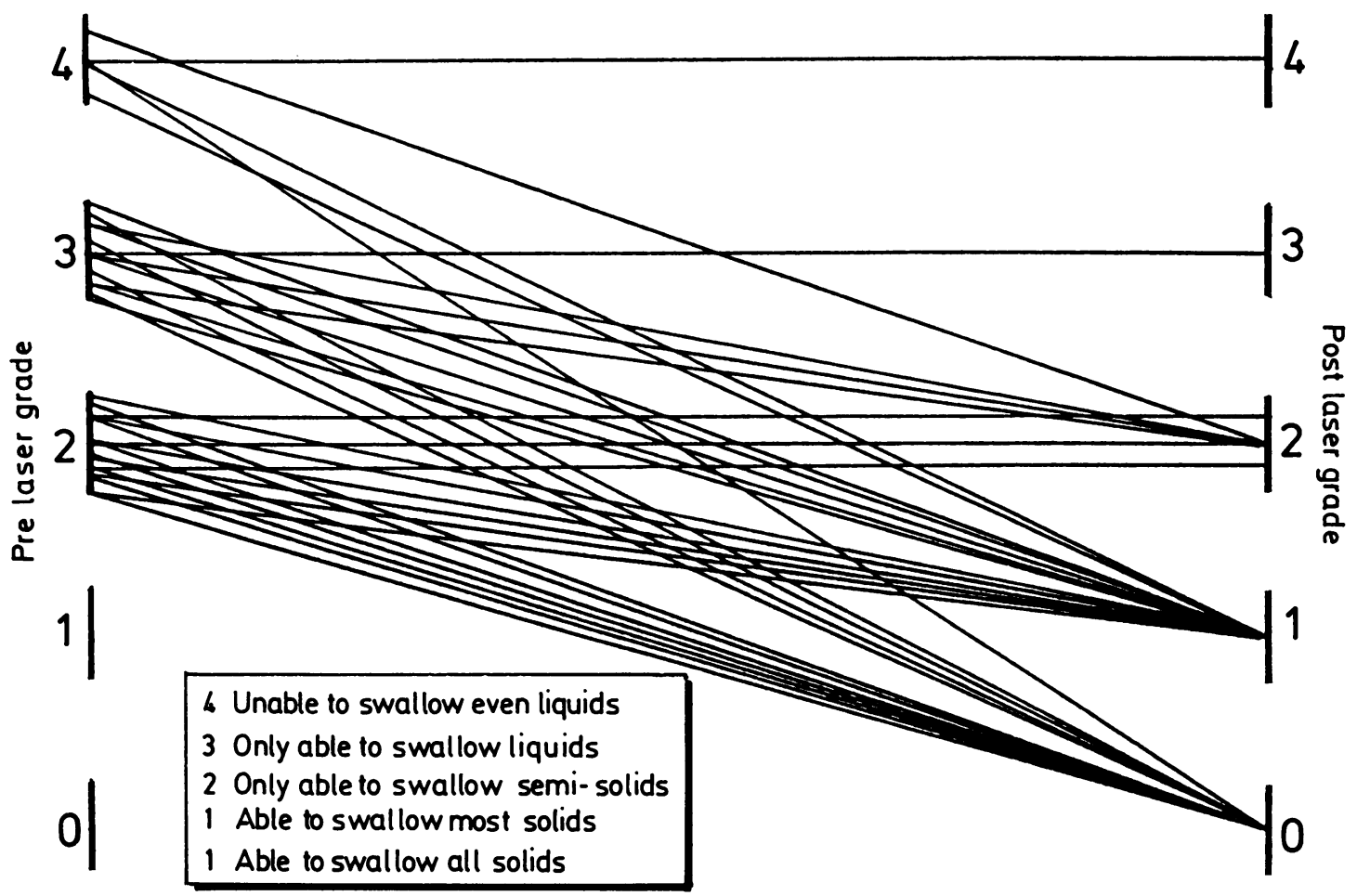

Fig. 2 Initial response of dysphagia to laser treatment.

yet to be fully assessed for oesophageal lesions. For some patients, the hospital stay is longer because their general condition is poor and suitable arrangements must be made for their care at home, but these are social factors which do not depend on the method of treatment used.

The only major complications related to laser treatment were two perforations $(6 \%)$ both of which occurred during an initial course of treatment. One was fatal. One occurred very early in the series during the fifth treatment in a patient with a $13 \mathrm{~cm}$ tumour, and perhaps reflected inexperience in a difficult situation. He did well after a surgical gastric pull-up procedure. The second had a total obstruction at the cardia which prevented passage of a guide wire more than $1 \mathrm{~cm}$ below the lumen visualised endoscopically. This was recognised to be an extremely high risk situation, but as there were no reasonable alternatives, he was treated blindly with a sapphire tipped probe. He sustained a perforation and died a few days later. This technique was used successfully in another similar patient, however, presenting with complete obstruction and no identifiable lumen. After treatment the patient could swallow semisolids, and lived comfortably at home for a further 20 weeks. This incidence of perforation is comparable with that of other series [Fleischer $5 \%,{ }^{17}$ Delvaux (in a multicentre review) $4 \%]^{19}$. These larger series identified further risk factors such as previous radiotherapy, acute angulation in a tumour at the cardia, and bougienage at the same session as laser treatment. The risk of perforation, however, should be kept very low if one is aware of these. Bougienage makes it possible to reduce the number of endoscopies required by improving endoscopic access and is a most useful technique if appropriately employed, although some authors prefer to avoid its use. ${ }^{9}$ The incidence of perforation after intubation is higher at $9-11 \% .^{216}$ The mortality from procedure related complications is $2-16 \%$ after intubation ${ }^{21620121}$ but only $1-5 \%$ after laser." "11"

The quality of swallowing is notoriously difficult to quantify as it is difficult to assess objectively. The best simple approach is to use the five grades shown in Figure 2. With a prosthetic tube in place there is inevitably a rigid section of the oesophagus through which food must pass solely under the influence of gravity. With commercially available tubes, this is typically $11-12 \mathrm{~mm}$ in diameter and $10-12 \mathrm{~cm}$ long. Swallowing in these patients is helped by frequent 
sips of carbonated drinks, the bubbles acting as a lubricant. In Ogilvie's series, $58 \%$ could swallow most solids and a further $8 \%$ all solids after intubation $^{16}$ but it is doubtful if any of these individuals could adopt entirely normal eating habits without a risk of tube blockage. Watson reported that only $33 \%$ could take solids after intubation. ' Some further improvement may be possible by using tubes tailor made for individual tumours, ${ }^{2-}$ but there must always be a rigid section of the oesophageal wall.

The quality of swallowing after laser treatment is more variable, as it depends on the nature and extent of the diseased areas of oesophagus remaining. If the tumour is not circumferential, then it may be possible for peristaltic waves to pass the full length of the organ, and if exophytic tumour has been cleared, swallowing can be close to normal. It would be difficult to do better than one of our patients who commented that nine months after treatment he felt the occasional piece of steak catch on something as it went down. A long and circumferential lesion may develop into a rigid, aperistaltic tube after therapy, however, with the same functional result as a prosthetic tube. Twelve of our patients $(35 \%)$ ate a normal diet after treatment and a further $13(38 \%)$ could swallow most solids, although some commented that they had to eat slowly. These results are very similar to Mellow and Pinkas' figures of $43 \%$ and $33 \%$ respectively. ${ }^{9}$

There are some patients who have continuing dysphagia after treatment despite re-establishment of luminal patency. This occurs particularly with high cervical lesions after previous radiotherapy (perhaps because of damage to pharyngeal muscles). Severe pretreatment anorexia, in contrast with the dysphagia, seldom responds to endoscopic treatment. ${ }^{9}$ Thus overall, about one third of patients are restored to an eating pattern close to normal and probably better than anything that can be achieved by intubation, and another third can eat most solids, comparable with those with a tube. Fleischer ${ }^{6}$ reports results equivalent to these two groups of ours in 48 of
60 patients $(80 \%)$, Mellow ${ }^{14}$ in eight of $10(80 \%)$ and Riemann" in 14 of $18(78 \%)$. Nevertheless, a true comparison of the quality of swallowing after intubation or laser treatment can only come from a randomised, controlled trial. One such trial has been reported, which suggested that swallowing was better after laser therapy, although the total number of patients included was only $20 .^{23}$

The value of palliation for malignant dysphagia depends not only on the immediate result of treatment, but on the period for which symptomatic benefit persists and the need for subsequent intervention to treat recurrence. This aspect is poorly covered in most of the reports of endoscopic therapy so far published. In Ogilvies series, ${ }^{16}$ of the 102 patients discharged after successful intubation, $51(50 \%)$ had recurrent dysphagia or late procedure related complications. Eighteen had blocked tubes, 17 had displaced or damaged tubes and in seven the tumour grew over the tube. All these were treated by unblocking or replacing the tube except three of the tumour overgrowths. Nine patients died from late perforations because of pressure necrosis from the tube. In our series there were no late deaths related to the initial procedure but of the 28 patients who had a first successful course of laser treatment without any other immediate therapy, $18(64 \%)$ required subsequent intervention (four patients who have received only one laser course are still alive, and so could yet develop further dysphagia). Although 10 of these with recurrence did well after further laser treatment, eight had no exophytic tumour at repeat endoscopy and needed alternative therapy (Table 2). These results are compared with those in other series in Table 4. The need for further intervention and the use of further laser treatment or intubation are similar. In the present series, however, the fact that those who had further laser treatment did so after a mean of five weeks whereas those needing alternative later intervention did so after a mean of 10 weeks suggests that the former group may have had inadequate laser treatment in the first course. The longer

Table 4 Recurrent dysphagia and subsequent management in published series

\begin{tabular}{|c|c|c|c|c|c|c|}
\hline & $\begin{array}{l}\text { Patients with successful } \\
\text { initial laser treatment } \\
\text { (n) }\end{array}$ & $\begin{array}{l}\text { Recurrent dysphagia } \\
\text { requiring treatment (n) }\end{array}$ & $\begin{array}{l}\text { Time from initial } \\
\text { treatment to } 2 \text { nd } \\
\text { intervention }(w k)\end{array}$ & $\begin{array}{l}\text { Furtherlaser } \\
\text { therapy }\end{array}$ & $\begin{array}{l}\text { Endoscopic } \\
\text { intubation }\end{array}$ & $\begin{array}{l}\text { Other } \\
\text { treatment }\end{array}$ \\
\hline Mcllow ${ }^{14}$ & 11 & 5 & $10(4-15)$ & 5 & - & - \\
\hline Ricmann ${ }^{10}$ & 14 & 8 & $5(4-6)$ & 3 & 4 & 1 \\
\hline Present series & $28^{*}$ & 18 & $6(2-15)$ & 10 & 8 & - \\
\hline
\end{tabular}

${ }^{*}$ One patient with successful laser treatment who had carly intubation to protect the lumen during radiotherapy has been excluded.

These series include some patients who were still alive at the time of publication. and so in the final analysis. the incidence of recurrent dysphagia could be higher. 
interval before recurrence in Buset's series ${ }^{7}$ may reflect patient selection as his tumours were shorter in length and presumably treated at an earlier stage.

In our series, those unsuitable for further treatment by laser were treated by dilatation and insertion of a Celestin tube, but four had major complications. The three intubation related deaths (pneumonia, postanaesthesia and one perforation) were attributable at least in part to the advanced state of the malignancy, but the other perforation occurred in a patient who was not terminal. In this case, the endoscopic appearance was that of a benign peptic stricture at the gastrooesophageal junction and a gastrografin swallow showed that the leak was not at the site of the stricture, but in a normal area of cervical oesophagus. It was thought that the tear had been caused by bowing of the flexible Celestin dilator while applying pressure to dilate a tough fibrous stricture. Tissue for histology was not available in this case, but a post mortem section from a patient who died nine months after successful laser treatment is shown in Figure 3. Although tumour is still present in the treated area, there is a considerable amount of fibrosis, which can be attributed to laser effects (this patient did not have any radiotherapy). This is similar to the scarring that has been documented in normal gastric tissue after exposure to the Nd YAG laser. ${ }^{24}$ It would appear that this fibrosis can be both beneficial and detrimental. In all post mortem tissue examined from patients who had had good long term palliation from the laser, there was considerable fibrosis in the treated areas immediately adjacent to the oesophageal lumen, and it seems likely that this had helped to reduce intraluminal regrowth. In the patients with the benign looking strictures, however, this fibrous tissue probably contracted, perhaps exacerbated by reflux oesophagitis which can occur after successful recanalisation of a tumour at the cardia, because of destruction of the normal antireflux mechanism and which we have documented in other patients.

These observations suggest ways in which the incidence of recurrent dysphagia after laser therapy might be reduced. Once debulking has been achieved, if all further areas of obviously neoplastic mucosa are treated, this could reduce exophytic recurrence. This must be done carefully as the objective at this stage is not to produce further debulking, but rather to stimulate an inflammatory response that leads to local replacement of tumour by scar tissue. The laser power and exposure time should be chosen to blanch but not char the previously untreated neoplastic areas, although the best parameters to achieve this have not yet been established. It is not always possible to identify all relevant areas at the time of initial recanalisation and it is now

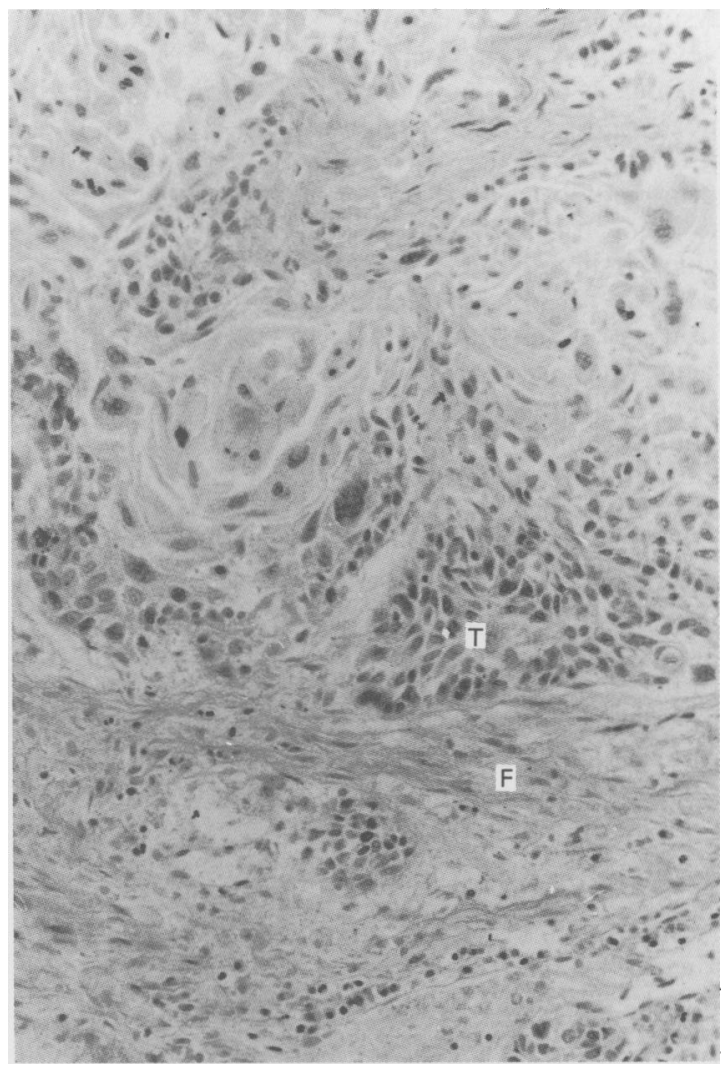

Fig. 3 Section of oesophagus (post mortem), taken nine months after successful laser treatment. T: viable tumour. F: fibrosis. $(H \& E)$.

our policy to repeat endoscopy two to four weeks after the initial laser course to treat any further accessible tumour. Fibrous strictures seem most likely to form after treatment of circumferential tumours that cross the gastrooesophageal junction. Their incidence might be reduced by vigorous antireflux measures, but in these cases, routine follow up endoscopies to identify fibrous narrowing before it causes symptoms might be wise as dilatation at this stage should be simple and safe. Our patients in this category had problems five to 15 weeks after initial therapy so a reasonable regime for them would be monthly check endoscopies for the first four months. Nevertheless, many of the recurrences in which exophytic tumour is not seen are caused by compression of the oesophagus by extrinsic tumour, and these can only be helped by a prosthetic tube (if it is technically possible to insert this).

It has become clear that the major problem with laser recanalisation is the high incidence of recurrent 
dysphagia after a relatively short period of time. Nevertheless, some patients can eat normally for as long as nine months after treatment, and the measures outlined above may increase the dysphagia free interval for many of the others. For good long term palliation in a high percentage of patients, however, it is necessary to treat tumour beyond that which is immediately accessible to the laser endoscopist with present techniques. In the immediate future, a combination of laser and non-laser methods seems the most promising approach. Recent reports suggest that intracavitary irradiation can treat extraluminal tumour without the high morbidity associated with external beam radiotherapy. Techniques are available for applying intense local irradiation via a transnasal tube positioned endoscopically. In a report of 48 cancers treated by laser recanalisation followed by afterloading irradiation, only $11(23 \%)$ had recurrent dysphagia, although follow up times for the 32 patients still alive are not given. Those who died survived an average of six months. ${ }^{25}$ Another series treated by intracavitary irradiation alone had relief of symptoms for 8-50 weeks (average 14 weeks), although the time after treatment before relief of dysphagia occurred is not given..$^{2 n}$ In our present state of knowledge, laser therapy is complementary to endoscopic intubation in the palliation of advanced malignant dysphagia. The quality of palliation after laser treatment can be extremely good, but more studies are required to achieve and maintain this in a high percentage of patients, and may well involve the use of additional methods such as intracavitary irradiation.

We should like to thank our many colleagues in this and other hospitals for referring these cases, and for help in documenting their follow up. We should also like to thank Sister Ramu and the staff of the Endoscopy Unit at University College Hospital for their continual help and support, Dr T N Mills from the Department of Medical Physics for technical help and Miss $\mathbf{J}$ Forster for preparing the manuscript. This work was supported by the Imperial Cancer Research Fund (Dr S G Bown), the DHSS (Dr K Matthewson and Dr C P Swain) and the Wellcome Trust (Mr H Barr).

\section{References}

1 Earlam R, Cunha-Melo JR. Oesophageal squamous cell carcinoma I. A critical review of surgery. Br J Surg 1980; 67: $381-9()$.

2 Watson A. A study of the quality and duration of survival following resection, endoscopic intubation and surgical intubation in oesophageal carcinoma. BrJ Surg 1982; 69: 585-8.

3 Earlam R, Cunha-Melo JR. Oesophageal squamous cell carcinoma II. A critical review of radiotherapy. $\mathrm{Br} J$ Surg 1980; 67: 457-61.

4 Tytgat GN, den Hartog Jager FCA. To dilate or intubate. Gastrointest Endosc 1983; 29: 58.

5 Lux G, Groitl H, Ell C. Tumour stenoses of the upper gastrointestinal tract - therapeutic alternatives to laser therapy. Endoscopy 1986; 18: suppl 1: 37-43.

6 Fleischer D, Kessler F, Haye O. Endoscopic Nd YAG laser therapy for carcinoma of the esophagus: A new palliative approach. Am J Surg 1982; 143: 28()-3.

7 Buset M, Dunham F, Baize M, de Toeuf J, Cremer M. $\mathrm{Nd}$ YAG laser - a new palliative alternative in the management of esophageal cancer. Endoscopy 1983; 15: 353-6.

8 Krasner N, Beard J. Laser irradiation of tumours of the oesophagus and gastric cardia. Br Med J 1984; 288: 829-30.

9 Mellow MH, Pinkas H. Endoscopic laser therapy for malignancies affecting the esophagus and gastroesophageal junctions. Analysis of technical and functional efficacy. Arch Intern Med 1985; 145: 1443-6.

10 Riemann JF, Ell C, Lux G, Demling L. Combined therapy of malignant stenoses of the upper gastrointestinal tract by means of laser beam and bougienage. Endoscopy 1985; 17: 43-8.

11 Ell C, Riemann JF, Lux G, Demling L. Palliative laser treatment of malignant stenoses in the upper gastrointestinal tract. Endoscopy 1986; 18: suppl 1:21-6.

12 Mathus-Vliegen EMH, Tytgat GN. Laser photocoagulation in the palliative treatment of upper digestive tract tumours. Cancer 1986; 57: 396-9.

13 Ell C, Hochberger J, Lux G. Clinical experience of noncontact and contact Nd YAG laser therapy in inoperable tumour stenoses of the oesophagus and stomach. Lasers Med Sci 1986; 1: 143-6.

14 Mellow MH, Pinkas H. Endoscopic therapy for esophageal carcinoma with Nd YAG laser: prospective evaluation of efficacy, complications and survival. Gastrointest Endosc 1984; 30: 334-39.

15 Fleischer D, Kessler F. Endoscopic Nd YAG laser therapy for carcinoma of the esophagus: a new form of palliative treatment. Gastroenterology 1983; 85: 600-6.

16 Ogilvie AL, Dronfield MW, Ferguson R, Atkinson M. Palliative intubation of oesophagogastric neoplasms at fibreoptic endoscopy. Gut 1982; 23: 106()-7.

17 Fleischer D, Sivak MV. Endoscopic Nd YAG laser therapy as a palliation for esophagogastric cancer. Gastroenterology 1985; 89: 827-30.

18 Hetzel MR, Nixon C. Edmonstone WM et al. Laser therapy in 100 tracheobronchial tumours. Thorax 1985 : 40: $341-5$.

19 Delvaux M, Escourrou J. Complications observed during laser treatment of tumours of the upper digestive tract. Acta Endoscopica 1985; 15: 13-8.

20 den Hartog Jager FCA. Bartelsman JFWM. Tytgat GNJ. Palliative treatment of obstructing esophagogastric malignancy by endscopic positioning of a plastic prosthesis. Gastroenterology 1979: 79: 10)8-14.

21 Jones DB. Davies PS. Smith PM. Endoscopic insertion of palliative oesophageal tubes in oesophagogastric neoplasms. Br J Surg 1981; 68: 197-8.

22 Tytgat GN, den Hartog Jager FCA. Ergebnisse der 
endoskopischen Implantation von Uberbruckungstuben. Dtsch Arzteblatt 1982; 79: 49.

23 Carter R, Smith J. A comparative study of laser recanalisation versus intubation in the palliation of gastroesophageal carcinoma. Lasers Med Sci 1986; 1: 245-51.

24 Kelly DF, Bown SG, Calder BM, et al. Histological changes following Nd YAG laser photocoagulation of canine gastric mucosa. Gut 1983; 24: 914-20.
25 Bader M, Dittler HJ, Ultsch B, Ries G, Siewert JR. Palliative treatment of malignant stenoses of the upper gastrointestinal tract using a combination of laser and afterloading therapy. Endoscopy 1986; 18: suppl 1: 27-36.

26 Rowland CG, Pagliero KM. Intracavitary irradiation in palliation of carcinoma of oesophagus and cardia. Lancet 1985; ii: $981-3$. 